\title{
Compensation in Epitaxial Cubic SiC Films
}

B. Segall

Case Western Reserve University

Cleveland, Ohio

and

S.A. Alterovitz, E.J. Haugland, and L.G. Matus

Lewis Research Center

Cleveland, Ohio

LIBRARY BUPY

APR $4 \quad 1986$

LANGLEY RESEARCH CENTER

LIRRARY, NASA

HAM:IPTON, VIRGINIA

March 1986 
COMPENSATION IN EPITAXIAL CUBIC SIC FILMS

\author{
B. Segal! \\ Case Western Reservè University \\ Physics Department \\ Cleveland, Ohio 44706
}

and

S.A. Alterovitz, E.J. Haugland, and L.G. Matus National Aeronautics and Space Administration

Lewis Research Center

Cleveland, Ohio 44135

\begin{abstract}
Hall measurements on four n-type cubic SiC films epitaxially grown by chemical vapor deposition on (100) SiC substrates are reported. Detailed analyses of the temperature dependent carrier concentrations indicate that the samples are highly compensated (>90 percent), contrary to the assumption of no compensation made in previous studies of similarly prepared sic films. Donor fonization energies, $E_{D}$, are found to be less than one half the values previously reported. The values for $E_{D}$ and the donor concentration $N_{D}$, combined with results for small bulk platelets with nitrogen donors, suggest the relation $E_{D}\left(N_{D}\right)=E_{D}(0)-\alpha N_{D}^{1 / 3}$ for cubic sic. A curve fit gives $\alpha \cong 2.6 \times 10^{-5} \mathrm{meV} \mathrm{cm}$ and $E_{D}(0) \cong 48 \mathrm{meV}$, which is the generally accepted value of $E_{D}(0)$ for nitrogen donors in cubic SiC.
\end{abstract}

$$
N 86-25267^{4}
$$


Cubic silicon carbide $(B-S i C)$, a wide bandgap semiconductor with high electric breakdown field, high saturated drift velocity, and high thermal conductivity, is an attractive electronic material for high temperature, high power and/or high frequency applications. 1 These potentialities unfortunately have been difficult to realize due to the unavallability of reasonably large crystals. The recent development of a technique for growing large area crystal films on (100) Si substrates has renewed interest in cubic Sic. ${ }^{2}$ others have since reported similar results. ${ }^{3-5}$ The temperature dependence of carrier concentration in cubic Sic films has been measured using Hall effect ${ }^{4}$ and cyclotron resonance techniques. ${ }^{6}$ The results of these studies were analyzed assuming that these n-type cubic Sic films were uncompensated. A similar assumption was also made in a study of cubic SiC platelets. 7 The authors find that the conductivity is due to the presence of donors with ionization energies, $E_{D}$, roughly equal to 40 to $50 \mathrm{meV}$. The donor has been identified as nitrogen, which, in small high purity crystals is found to have an ionization energy, $E_{D}$, of $54 \mathrm{meV}^{8}$

In the present work we report Hall measurements on four film samples with mobilities as high as any previousiy reported. In our analysis, which focuses on the carrier concentrations $n(T)$, we find, contrary to the assumption made in previous work, ${ }^{4,6,7}$ that the material is highly compensated. We also find that $E_{D}$ is much less than one-half the values quoted earller. Thus, our determination of the values of the key parameters characterizing the electrical properties, namely the donor and acceptor concentrations $N_{D}$ and $N_{A}$, and $E_{D}$, differ markedly from those resulting from the noncompensation assumption. However, we do find evidence identifying the donors as nitrogen.

The samples investigated were prepared by the method described earlier. ${ }^{2}$ All samples were roughly square with sides approximately $5 \mathrm{~mm}$ and 
thicknesses from 4.6 to $16.9 \mu \mathrm{m}$. Electrical contacts were made on each corner, in a square pattern and $2.5 \mathrm{~mm}$ apart, by sputter deposition of Ta/Au. Measurements of the resistivity and Hall coefficient were made with dc current using the van der Pauw technique. ${ }^{9}$ Appropriate averages were taken over all possible current and magnetic field reversals and all van der Pauw configurations to eliminate extraneous effects. Corrections for contact size and position were not made. Magnetic fields up to $13 \mathrm{kG}$ were used. The temperature was varied in a gas flow cryostat and stabilized to within $0.02 \mathrm{~K}$.

The carrier concentrations $n(T)$ were obtained from the Hall coefficient. Experimental results for three of the four samples studied are shown as points in Fig. 1. One of the samples (number 438 ), which was fairly thick $(16.9 \mu \mathrm{m})$ and hence capable of being separated from the substrate, was also subjected to high temperature ( $300 \mathrm{~K} \approx \mathrm{T} ₹ 800 \mathrm{~K})$ measurements on a different apparatus. Results for this sample are shown in Fig. 2. As some measure of the quality of the samples, we note that the room temperature mobilities for sample numbers $340,437,438$, and 503 are $270,310,305$, and $245, \mathrm{~cm}^{2} / \mathrm{sec}$, respectively. The data for $T \leq 50 \mathrm{~K}$ exhibit a flattening out, which apparently is associated with impurity band conduction. The van der Pauw ratio was quite constant over the relevant temperature range, with deviations of \pm 7 percent from the mean value for samples 340 and 503 and about \pm 70 percent for samples 437 and 438 .

While the rough linearity of $\log n(T)$ for $T \Im 50 K$ makes the assumption $n \propto \exp \left[-E_{D} / 2 k T\right]$ tempting, a thorough and unbiased analysis is required, especially since $E_{D}$ is small. Here we use the appropriate relation

$$
\frac{n\left(n+N_{A}\right)}{N_{D}-N_{A}-n}=\frac{N_{C}}{S} \exp \left(-E_{D} / k T\right)
$$

which is accurate for a single level and nondegenerate carriers. Relevant information regarding the conduction band minima obtained from luminescence 
Zeeman studies $^{8}$ show that they lie along $\left.<100\right\rangle$ axes, presumably on a $\Delta_{1}$ band. The nondegeneracy of $\Delta_{1}$ implies that the spin degeneracy factor $s$ is 2. The conduction band density of states $N_{c}$ is $N_{c}=$ $2 M\left(2 \pi m_{d} k T\right)^{3 / 2} h^{-3}$ where $M$ is the number of equivalent minima and $m_{d}$ is the "density of states effective mass" given by $\left(m_{t}^{2} m_{\ell}\right)^{1 / 3}$ with $m_{t}$ and $m_{\ell}$ being the transverse and longitudinal effective masses. The values $m_{t}=0.247 \mathrm{~m}_{0}$ and $m_{l}=0.677 \mathrm{~m}_{0}$ determined by cyclotron resonance measurements, ${ }^{7}$ wich are within a few percent of those found in the magneto-optical studies, ${ }^{8}$ yieid $m_{d} \equiv 0.346 m_{0}$. Since symmetry requires that the end of the $\langle 100\rangle$ axis be an extremum, it is very reasonable to expect the minima to be at the zone boundary and thus $M$ $=3$. The fitting of $n(T)$ is obtained by suitable adjustments of $E_{D}$, $N_{D}$, and $N_{A}$.

Our fits of the data are shown by the solid curves in Figs. 1 and 2: They clearly provide very satisfactory representations of the data except for the temperature range exhibiting impurity band conduction, which, of course, must be treated separately. The values for $E_{D}, N_{D}$, and $N_{A}$ yielding these curves are given in Table $I$.

The first point evident from the tabulation is that the samples are highly compensated with $N_{A} / N_{D}>0.9$. The second is that the values of $E_{D}$ are much smaller than (less than one-half) the published film values and the generally accepted value for the nitrogen donor ( $\approx 50 \mathrm{meV})$. It is reasonable here to raise the question of the uniqueness of our fits and, in particular, of the possibility of achieving a comparably good fit assuming no compensation over the relevant range of temperature $T$. Considering the different T-dependence resulting from the assumption of no compensation, that seems unlikely. Indeed, our attempts at achieving such fits, as illustrated by the dashed curve in Fig. 2 for sample number 438 , bear out that 
expectation. The dashed curve is required to agree with the experimental data in the "saturation" region and in the middle; of the region exhibiting "freeze out." The values obtained for the dashed curve are $N_{0} \approx 1.6 \times 10^{17} \mathrm{~cm}^{-3}$ and $E_{D} \approx 48 \mathrm{meV}$, the latter being close to the value for nitrogen donors. The agreement, however, is clearly much less satisfactory than for the solid curves, with deviation reaching roughly 40 percent. While different requirements could be imposed, agreement nearly as good as that provided by solid curves does not seem possible. The above value of $E_{D}$ is more than twice (closer to three times) that obtained with compensation. This fact is due to the T-dependence of $\mathrm{N}_{\mathrm{C}}$ which has an appreciable effect for low values of $E_{D}$.

Another point evident in the tabulation is the variation of $E_{D}$ with $N_{0}$. That variation, while admittedly small because of the limited range of impurity concentration in our samples, is nevertheless significant when the present values are combined with those obtained by Aivazova et al. 10 from a study of small platelets of cubic SiC. In Fig. 3 we plot all these energies, $E_{D}$, versus $N_{D}$. Aside from some scatter, the $E_{D}$ points lie on a curve which extrapolates to the value of the nitrogen donor at $N_{0} \rightarrow 0$ and vanishes at $N_{D}=\bar{N}_{D}$, slightly above those of our samples.

Such a curve can be represented by the relation used for shallow acceptors in $\mathrm{Si}^{11}$ and shallow donors in $\mathrm{Ge}, 12$

$$
E_{D}\left(N_{D}\right)=E_{D}(0)-\alpha N_{D}^{1 / 3}
$$

Here $E_{D}(0) \simeq 48 \mathrm{meV}$ and $\alpha=2.6 \times 10^{-5} \mathrm{meV} \mathrm{cm}$. Noteworthy is the closeness of our $\alpha$ to that reported for donors in $6 e^{12}\left(2.34 \times 10^{-5} \mathrm{meV}\right.$ $\mathrm{cm}$ ) and to the value we obtained by fitting Eddolls' curve ${ }^{14}$ for shallow donors in GaAs $\left(2.5 \times 10^{-5} \mathrm{meV} \mathrm{cm}\right)$.

Additional confirmation for our results follow from the condition $E_{D}\left(\bar{N}_{D}\right)=0$ namely, that the average interimpurity distance equal twice the 
effective Bohr radius of the donor. In the effective mass approximation we find $\bar{N}_{D} \approx 10^{79} \mathrm{~cm}^{-3}$. This agrees satisfactorily with the value $6.3 \times 10^{18} \mathrm{~cm}^{-3}$ indicated by the curve. Finally, since the magnitude of $E_{D}(0)$ agrees satisfactorily with the accepted value of the nitrogen donor at dilute concentration ${ }^{8}$ and since Aivazova et al. ${ }^{10}$ have identified their donors as nitrogen by ESR measurements, the above correlation suggests the same identification for the donors in our samples. Considering the preparation conditions for the present samples, nitrogen contamination seems reasonable.

In conclusion, we have found a high degree of compensation and a large impurity concentration induced reduction of the nitrogen donor depth in all samples. This enhanced understanding of the present state of cubic sic films should be helpful in their development for electronic applications.

\section{ACKNOWLEDGMENT}

Thanks are due to J.A. Powell for supplying the cubic Sic samples used in this study and to H.A. Will who sputter-deposited the electrical contacts on the samples. 


\section{REFERENCES}

1. W.C. Nieberding, Ind. Res. Dev., 25 (9) $\dddot{1}^{148}$ (1983): J.D. Parsons, R.F. Bunshah and 0.M. Stafsudd, Solid State Technol., 28 (11) 133, (1985).

2. S. Nishino, J.A. Powell and H.A. Wi11, Appl. Phys. Lett., 42, 460 (1983).

3. A. Addamiano and P.H. Klein, J. Cryst. Growth, 70, 291 (1984).

4. K. Sasaki, E. Sakuma, S. Misawa, S. Yoshida, and S. Gonda, Appl. Phys. Lett, $\underline{45}, 72(1984)$.

5. H.P. Liaw, and R.F. Davis, J. Electrochem., Soc., 131, 3014 (1984).

6. R. Kaplan, R.J. Wagner, H.J. Kim, and R.F. Davis, Solid State Commun., $\underline{55}, 67(1985)$.

7. A. Rosengreen, Mater. Res. Bul1., 4, S355 (1969).

8. P.J. Dean, W.J. Choyke and L. Patrick, J. Lumin., 15, 299 (7977).

9. L.J. van der Pauw, Philips, Res. Rep., 13, 1 (1958).

10. L.S. Aivazova, S.N. Gorin, V.G. Sidyakin, and I.M. Shvarts, Sov. Phys. Semicond. (Engl. Trans7.), 11, 1069 (1977).

11. G.L. Pearson, and J. Bardeen, Phys. Rev., 75, 865, (1949).

12. P.P. Debye and E.M. Conwe11, Phys. Rev., 93, 693, (1954).

13. D.V, Eddolis, Phys. Status Solidi, 17, 67 (1966). 
TABLE I.

\begin{tabular}{|c|c|c|c|}
\hline Samp le & $1018^{\mathrm{ND}_{\mathrm{D}}} \mathrm{cm}-3$ & $1018^{N_{A},} \mathrm{~cm}^{-3}$ & $\begin{array}{l}\mathrm{E}_{\mathrm{D}}, \\
\mathrm{meV}\end{array}$ \\
\hline $\begin{array}{l}340 \\
437 \\
438 \\
502\end{array}$ & $\begin{array}{l}2.79 \\
1.76 \\
2.00 \\
2.15\end{array}$ & $\begin{array}{l}2.50 \\
1.60 \\
1.83 \\
1.97\end{array}$ & $\begin{array}{l}13.2 \\
17.2 \\
14.5 \\
14.6\end{array}$ \\
\hline
\end{tabular}




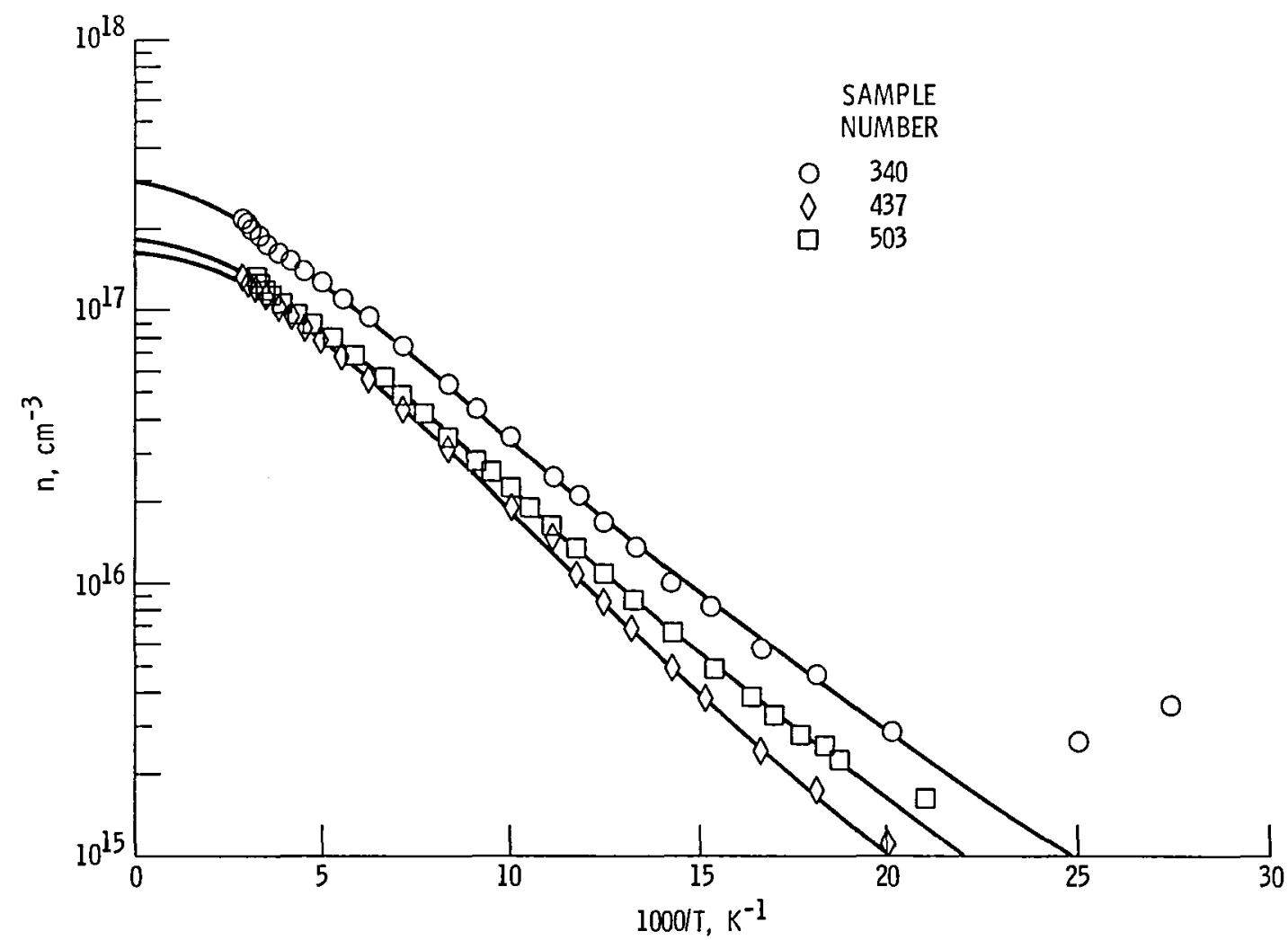

Figure 1. - Carrier concentration $n$ versus 1000/T for three cubic SiC samples. The points are experimental results while the continuous lines are calculated fits using compensation. 


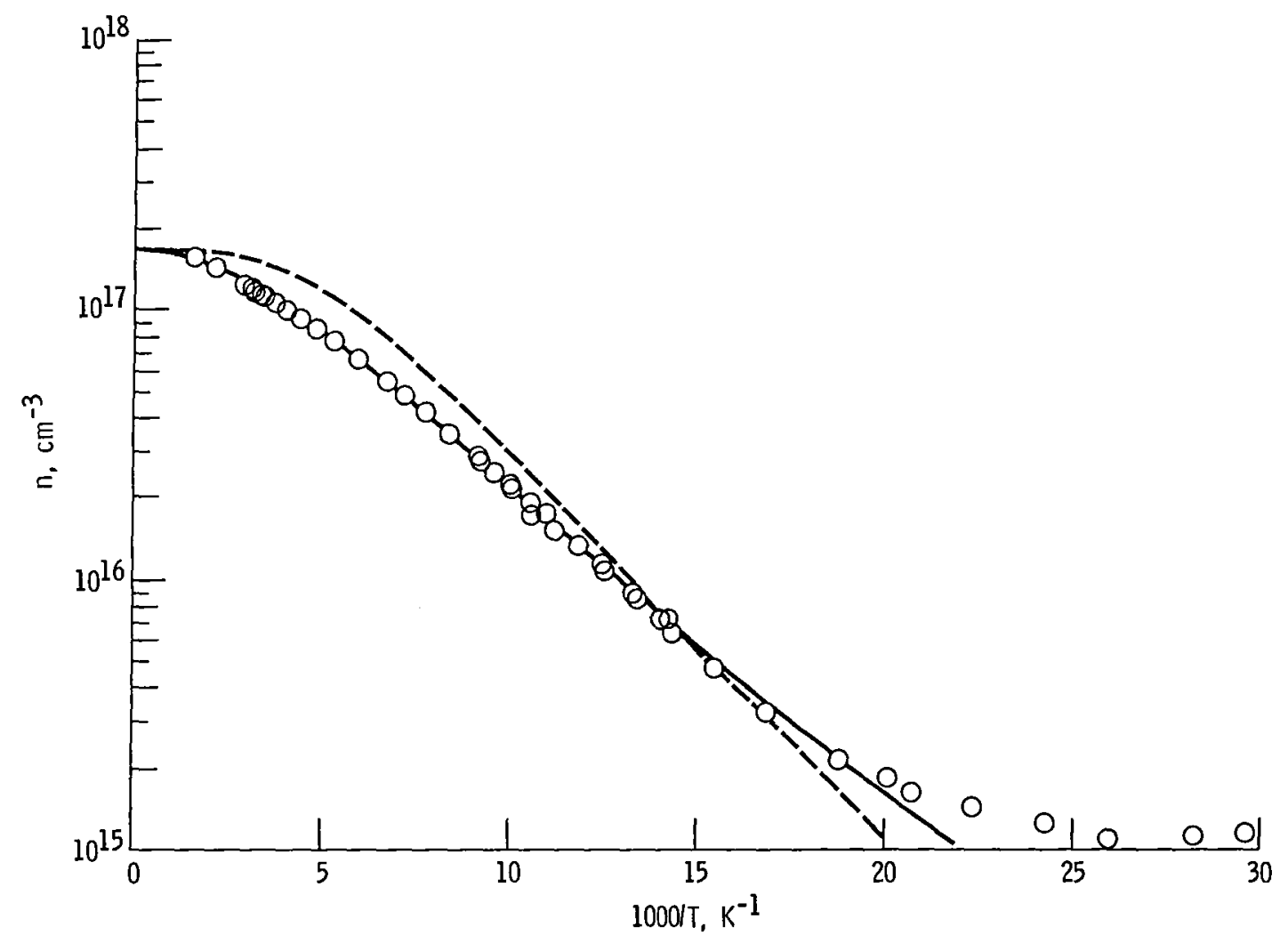

Figure 2. - Carrier concentration $n$ versus 1000/T for a self-supporting sample (number 438). The points are experimental results while the continuous and dashed lines are calculated fits using compensation and noncompensation, respectively.

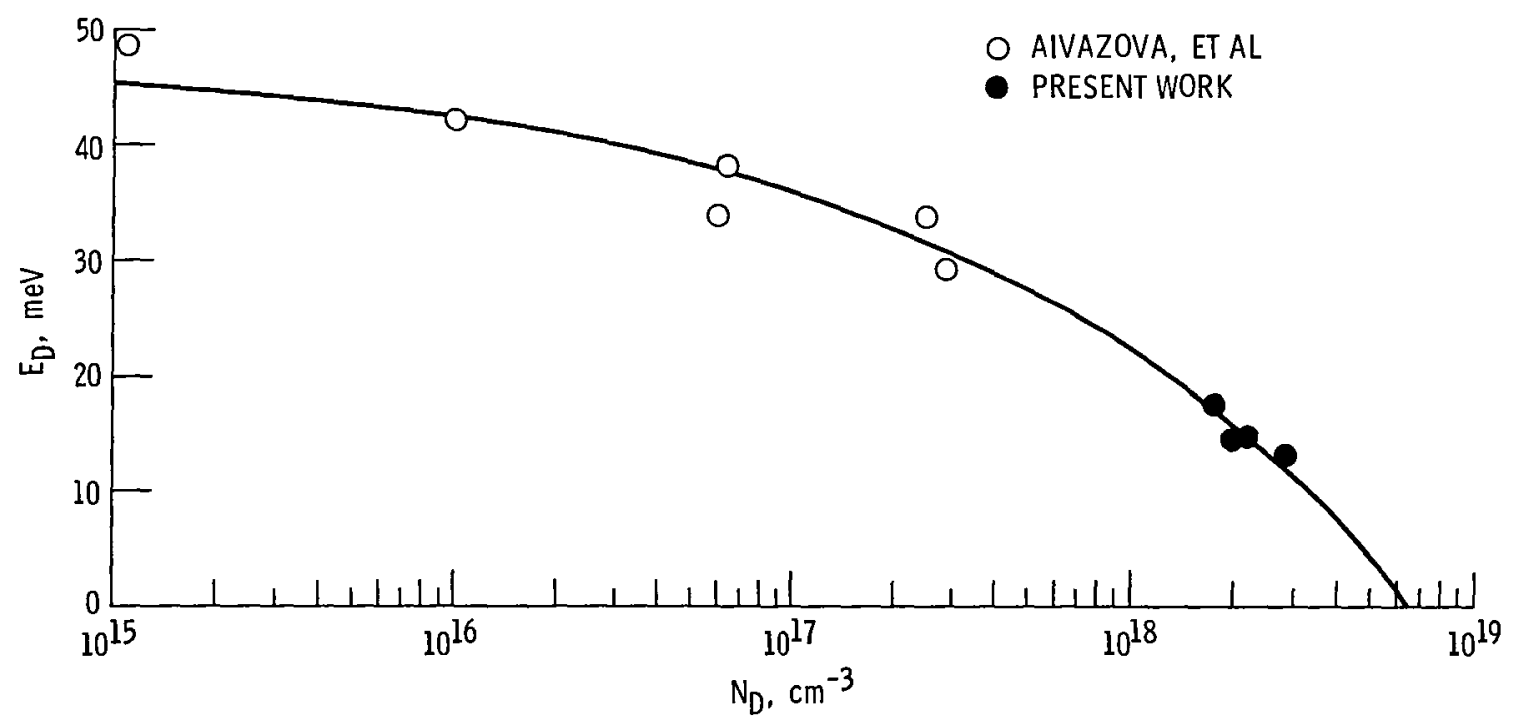

Figure 3. - Donor activation energy $E_{D}$ versus donor density $N_{D}$. The continuous line is given by equation (2) using $E_{D}(0)=48 \mathrm{meV}$ and $a=2.6 \times 10^{-5} \mathrm{meV} \mathrm{cm}$. 


\begin{tabular}{|c|c|c|}
\hline $\begin{array}{l}\text { 1. Report No. } \\
\text { NASA TM-87269 }\end{array}$ & 2. Government Accession No. & 3. Recipient's Catalog No. \\
\hline \multirow{2}{*}{\multicolumn{2}{|c|}{ Compensation in Epitaxial Cubic SiC Films }} & $\begin{array}{l}\text { 5. Report Date } \\
\text { March } 1986\end{array}$ \\
\hline & & $\begin{array}{l}\text { 6. Performing Organization Code } \\
506-44.22\end{array}$ \\
\hline \multirow{2}{*}{\multicolumn{2}{|c|}{$\begin{array}{l}\text { 7. Author(s) } \\
\text { B. Segall, S.A. Alterovitz, E.J. Haugland, and } \\
\text { L.G. Matus }\end{array}$}} & $\begin{array}{l}\text { 8. Performing Organization Report No. } \\
\text { E-2918 }\end{array}$ \\
\hline & & 10. Work Unit No. \\
\hline \multicolumn{2}{|c|}{$\begin{array}{l}\text { 9. Performing Organization Name and Address } \\
\text { National Aeronautics and Space Administration } \\
\text { Lewis Research Center } \\
\text { Cleveland, Ohio } 44735\end{array}$} & 11. Contract or Grant No. \\
\hline \multirow{2}{*}{\multicolumn{2}{|c|}{$\begin{array}{l}\text { 12. Sponsoring Agency Name and Address } \\
\text { National Aeronautics and Space Administration } \\
\text { Washington, D.C. } 20546\end{array}$}} & $\begin{array}{l}\text { 13. Type of Report and Period Covered } \\
\text { Technical Memorandum }\end{array}$ \\
\hline & & 14. Sponsoring Agency Code \\
\hline \multicolumn{3}{|c|}{$\begin{array}{l}\text { B. Segall, Case Western Reserve University, Physics Department, Cleveland, Ohio } \\
\text { 44106; S.A. Alterovitz, E.J. Haugland, L.G. Matus, Lewis Research Center. }\end{array}$} \\
\hline \multicolumn{3}{|c|}{ 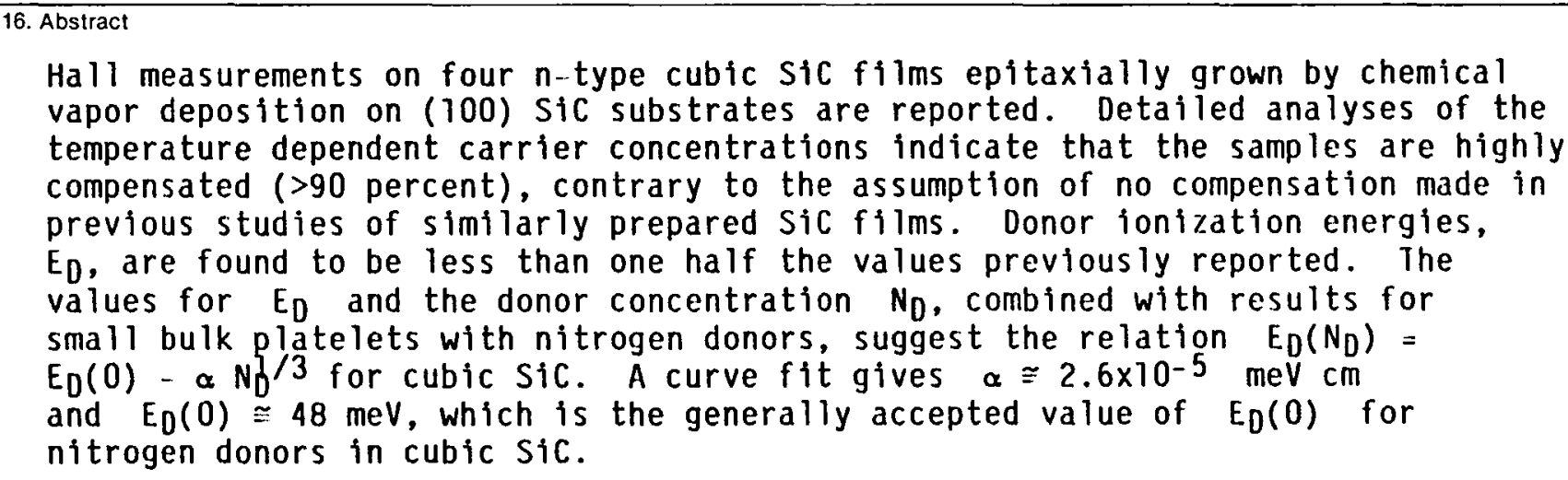 } \\
\hline $\begin{array}{l}\text { 17. Key Words (Suggested by Author(s)) } \\
\text { Compensation } \\
\text { Epitaxial films } \\
\text { Silicon carbide }\end{array}$ & $\begin{array}{l}\text { 18. Distri } \\
\text { Unc } \\
\text { STA }\end{array}$ & $\begin{array}{l}\text { ent } \\
\text { ry } 76\end{array}$ \\
\hline $\begin{array}{l}\text { 19. Security Classif. (of this report) } \\
\text { Unc las s if ied }\end{array}$ & $\begin{array}{l}\text { Security Classif. (of this page) } \\
\text { Unc lass if ied }\end{array}$ & 21. No. of pages \\
\hline
\end{tabular}

"For sale by the National Technical Information Service, Springfield, Virginia 22161 
End of Document 